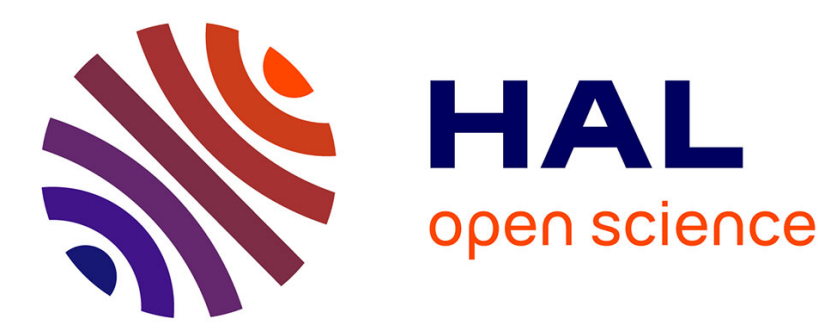

\title{
TOWARD A TOMOGRAPHIC ATOM-PROBE
}

\author{
A. Bostel, D. Blavette, A. Menand, J. Sarrau
}

\section{To cite this version:}

A. Bostel, D. Blavette, A. Menand, J. Sarrau. TOWARD A TOMOGRAPHIC ATOM-PROBE. Journal de Physique Colloques, 1989, 50 (C8), pp.C8-501-C8-506. 10.1051/jphyscol:1989886 . jpa00229984

\section{HAL Id: jpa-00229984 https://hal.science/jpa-00229984}

Submitted on 1 Jan 1989

HAL is a multi-disciplinary open access archive for the deposit and dissemination of scientific research documents, whether they are published or not. The documents may come from teaching and research institutions in France or abroad, or from public or private research centers.
L'archive ouverte pluridisciplinaire HAL, est destinée au dépôt et à la diffusion de documents scientifiques de niveau recherche, publiés ou non, émanant des établissements d'enseignement et de recherche français ou étrangers, des laboratoires publics ou privés. 


\author{
A. BOSTEL, D. BLAVETte, A. MENAND and J.M. SARRAU \\ Laboratoire de Microscopie Ionique, URA CNRS 808, BP. 118, F-76134 Mont \\ Saint Aignan, France
}

\begin{abstract}
Résumé : Le POSAP (Sonde Atomique munie d'un détecteur bidimensionnel) a ouvert la voie à l'exploration en trois dimensions des matériaux avec une résolution inférieure au nanomètre. Nous présentons un projet de Sonde Atomique Tomographique, basé sur le développement d'un détecteur multianodes avec mesure de la charge collectée sur chaque anode. Le but est d'enregistrer la position et le temps de vol des ions même lorsque ceux-ci sont produits par la même impulsion d'évaporation.
\end{abstract}

Abstract : The POSAP (Position Sensitive Atom Probe) has opened new outlooks for the three-dimensional analysis of materials with a resolution less than $1 \mathrm{~nm}$. This paper presents a project for a Tomographic Atom Probe, based on the design of a multianode detector and the measurement of collected charges for each anode. The goal is to register the position and the time of flight for every ion even for simultaneous events.

\title{
I. INTRODUCTION
}

Last year, at the 35th Field Emission Symposium [1], a new type of atom-probe giving spatial informations in a more quantitative way than the ones given by the IAP [2] was presented. By using a position sensitive detector, the oxford group succeeded in achieving a very attractive instrument : the POSAP. Despite the little difficulties which are encountered for the calculation of positions for simultaneous ions, the POSAP constitutes a new tool in material science which provides spectacular results (3). The potentialities of such an apparatus incited us to design as well as to develop an instrument of this new generation: the tomographic atom-probe.

For the design of such an apparatus, we started from the ideal requirements which follow:

The position sensitive detector should provide the coordinates of every ion generated on a single pulse with a spatial resolution close to $0.1 \mathrm{~nm}$. This includes the detection of chemical species with the same $M / n$. It is clear that these possibilities, require a refined detection device providing more numerous position data. In addition, a reduced dead time is needed.

- The mass resolution must be high enough for the unambiguous separation of chemical species.

- The sensitive area is high enough to observe relatively large microstructure features. The scanned volume which is planned is close to $(20 \times 20 \times 100) \mathrm{nm}^{3}$. 
of course, these performances are nothing but an ideal goal. In addition to the unavoldable need of a fast acquisition system, this project requires the use of a powerful computer. Spatial data as well as related times of flight must be treated in such a way to provide a convenient representation of atom-probe data : the stereographic images initially registred must be treated in a non curved Euclidian space. Tomographic sections with a defined thickness of the analysed volume are to be obtained and morphologic features of imaged phases have to be extracted as well.

It is quite evident that all these ideal conditions could be hard to fulfill. The design of such an instrument would be equivalent to the construction of a few $10^{4}$ atom-probes which constitutes a difficult project.

\section{BASIC PRINCIPLES OF THE ELEMENTAL DETECTOR}

The technical solution we would like to promote is based on the four sector detection system we presented four years ago at the 32nd IFES in Wheeling [4]. The basic idea is to measure the electronic charges which are stored in each elemental detector of a two-dimensional square shaped network. The computation of positions is based on the measurement of charges in a basic cell composed of four adjacent sectors (figure 1).

The detection area is positioned far from the back side of the channel-plate in such a way to obtain a defocused electron spot the size of which (R) is of the same order of magnitude as the sector dimensions.

By assuming for simplicity that the electron beam provided by the channel plate is homogeneously distributed. (i.e with a constant electronic density), electronic charges $\left(Q_{1}, Q_{2}, Q_{3}, Q_{4}\right)$ are connected to the spatial coordinates $(x, y)$ of the incoming ions as follows :

$$
\begin{aligned}
& \left.1^{\circ}\right) Q_{1}+Q_{3}=Q(1 / 2-G(X)) \\
& \left.2^{\circ}\right) Q_{3}+Q_{4}=Q(1 / 2-G(Y)) \\
& \left.3^{\circ}\right) Q=Q_{1}+Q_{2}+Q_{3}+Q_{4} \\
& \left.4^{\circ}\right) Q_{2}+Q_{3}=Q(1 / 2+2 X Y / \pi) ; X^{2}+Y^{2} \leqslant 1 . \\
& \text { with } G(X)=\frac{I}{\pi}\left[\arcsin X+X \sqrt{1-X^{2}}\right] \\
& \text { and } X=\frac{X}{R}, Y=\frac{y}{R}, \text { the reduced spot coordinates, }-1 \leqslant X \leqslant+1,-1 \leqslant Y \leqslant+1 .
\end{aligned}
$$

The experience is based on the measurement of four quantities $\left(Q_{i}, i=1,4\right)$. Among the four master equations, only the first three equations are necessary to calculate the three unknown variables ( $\mathrm{X}, \mathrm{Y}, \mathrm{Q}$ ). The additional equation (4) is no more valid when a sector is not triggered. However, it may be used to check the consistency of position data.

Position data are deduced from equations 1), 2), 3) as follows:

$$
X=G^{-1}\left[1 / 2-\left(Q_{1}+Q_{3}\right) / Q\right] \text { and } Y=G^{-1}\left[1 / 2-\left(Q_{3}+Q_{4}\right) / Q\right]
$$




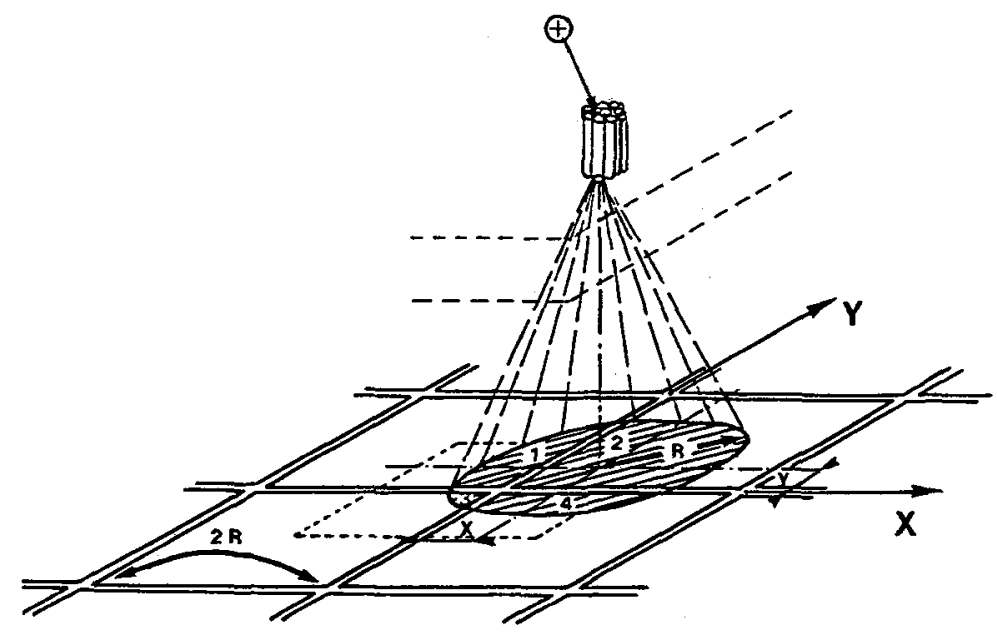

Figure 1 : Principle of the position sensitive multianode detector. Here the network parameter (a) is taken equal to the electron spot diameter (2R). The region limited by the dashed line is the sensitive area related to the sectors $1,2,3,4$. The position of the ions whose impact is outside of this area can be calculated from the charges collected in an other set of four sectors.

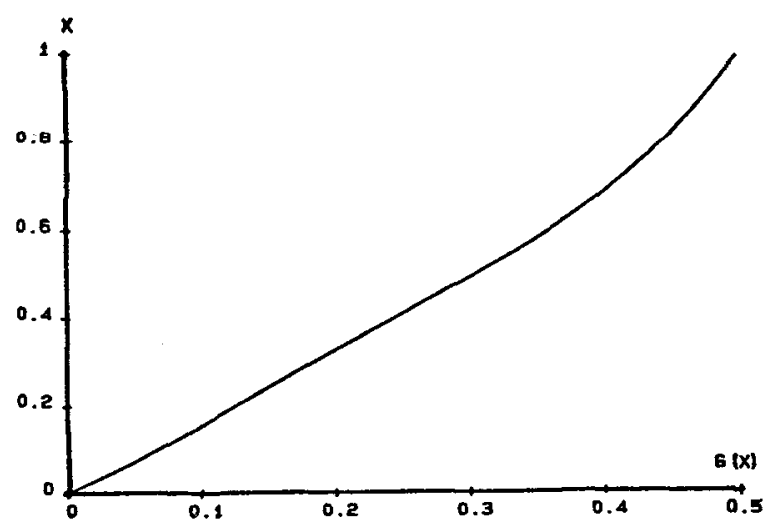

Figure 2 : Position $(X)$ of the ion impact as a function of the relative values of the charges which are collected on four adjacent sectors, $X=G^{-1}\left[1 / 2-\left(Q_{1}+Q_{3}\right) / Q\right]$.

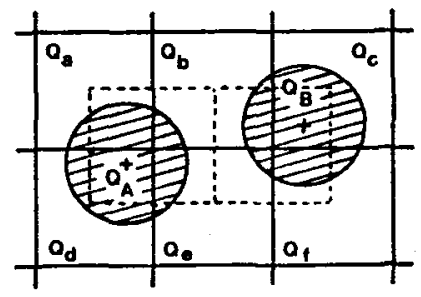

Figure 3 : This diagram shows a typical configuration for which six sectors are simultaneously involved by two ion impacts (A,B). The ion impacts are located in two adjacent sensitive areas (dashed lines). In this case, electronic charges stored in the two sectors $b$ and $e$ come from the two neighbour electron spots. Other configurations involving seven adjacent sectors may also be imagined. 
As $G$ function is a little cumbersome and difficult to inverse, we use a polynomial approximation of $\mathrm{G}^{-1}$. Figure 2 shows the aspect of this function. For a non homogeneous electron beam for which the revolution symetry is preserved, it is of course possible to include the radial electron density $g(r)$ of the spot. It is important to notice here, that the master equations obviously fail when only one sector is stimulated. For impacts which are outside of the sensitive square defined by $(X, Y)-(1,1)$, the position detector is no more operating (figure 1). In addition, when two ions (A, B) fall inside this sensitive square, the use of a single four section system is not sufficient to calculate the positions : it is not possible to deduce 6 parameters $\left(X_{A}, Y_{A}, Q_{A} / X_{B}, Y_{B}, Q_{B}\right)$ from only four equations (or four measurements). However, the use of the fourth equation (4) is now of utmost importance : when the consistency of position data is not verified, this suggests that more than one impact occur in the detection unit.

\section{THE ENTIRE DETECTION SYSTEM}

As only a single unit is not sufficient for multiple events, we propose to use a detëction network including say, a hundred sectors. Until now, the size of each sector has not been evoked. An electron spot with a diameter smaller than the grid spacing (a) would lead to undesirable uncertainties proportional to ( $-2 R$ ). In the opposite way, a much larger spot size gives an important number of measurements at the same time. Despite the set of data is more refined, the analytical resolution of the problem get more complex. The major disadvantage also is that the probability to have overlapped spots, increases ( $\sim \mathrm{R}^{2}$ ). For these reasons, the first approach we propose is simply based on a grid spacing (a) close to the spot diameter : $a \simeq 2 R$.

As we would want to design a tomographic system with intrinsic performances comparable to classical atom-probes, we will choose a typical acceptance angle of $20 \mathrm{mrad}$ for each elemental cell. This means that $a$ is equivalent to $2 \mathrm{~nm}$ for a tip radius of $50 \mathrm{~nm}$. For the sake of simplicity we will refer the detector dimensions to those of the analysed area on the tip. A possible configuration could be obtained with a $70 \mathrm{~mm}$ channel plate located at $350 \mathrm{~mm}$ from the tip. For an overall analysis area equivalent to $(20 \times 20) \mathrm{nm}^{2}$, the final electron collector is composed of a two dimensional array of (10 $x 10$ ) sectors.

\section{EVALUATION OF GENERAL PERFORMANCES}

The intrinsic performances of each detection cell is an important choice criterion. Because of the simple geometry, and contrary to the posap detector, the electrodes resistivity as well as the parasite capacities can and must be very low. Typical values would be an electrode resistance close to $0.01 \Omega$ and a capacity between two adjacent sectors around $0.01 \mathrm{pF}$. As a result, a dead time as low as the one of classical atom-probes may be obtained ( $10 \mathrm{~ns}$ ).

Because of the occurrence of pile-up effects [5], [6], a conventional atom-probe is usually operating with a detection flux close to 0.02 atom/pulse. In the same conditions, a tomographic atom-probe using 100 collectors will receive two ions per pulse in average. For the analysis of a pure metal with a single isotope and a single charge state, which constitutes the most drastic case, we have calculated that no overlap will occur in $90 \%$ of cases; the failure ratio corresponding to impacts located in the same sensitive area (figure 1 ) is close to $1 \%$. 
For the remaining cases $(9 \%)$, the position data (100) are numerous enough for the atom coordinates to be computed. For instance, when two ions (A, B) stimulate 6 adjacent sectors (figure 3 ), the charge measurements are sufficient for the problem to be solved. The following system of six equations shows for instance, the manner the six unknown data $\left(X_{A}, Y_{A}, Q_{A} / X_{B}, Y_{B}, Q_{B}\right)$ can be extracted from initial data.

$$
\begin{aligned}
& Q_{a d}=Q_{A}\left[1 / 2-G\left(X_{A}\right)\right] \quad Q_{c f}=Q_{B}\left[1 / 2+G\left(X_{B}\right)\right] \\
& Q_{d e f}=Q_{A}\left[1 / 2-G\left(Y_{A}\right)\right]+Q_{B}\left[1 / 2-G\left(Y_{B}\right)\right] \\
& Q_{a b c d e f}=Q_{A}+Q_{B} \\
& Q_{d b c}=Q_{A}\left[1 / 2+2 X_{A} Y_{A} / \pi\right]+Q_{B}\left[1 / 2+G\left(Y_{B}\right)\right] \\
& Q_{d e c}=Q_{A}\left[1 / 2-G\left(Y_{A}\right)\right]+Q_{B}\left[1 / 2+2 X_{B} Y_{B} / \pi\right] \\
& \text { with the notation } Q_{i j k}=Q_{i}+Q_{j}+Q_{k} \\
& \text { and } X_{A}, X_{B}, Y_{A}, Y_{B} \text { the local coordinates of } A \text {, B impacts. }
\end{aligned}
$$

These equations remain valid in the general case for which each impact (A, B) leads to four triggered sectors. When only three adjacent cells are stimulated $\left(X_{A}^{2}+Y_{A}^{2}>1\right.$ or $\left.X_{B}^{2}+Y_{B}^{2}>1\right)$, the fourth relation $\left(4^{\circ}\right)$ in master equations fails and this equation system must be replaced by six other mathematic relationships.

\section{ELECTRONICS AND TECHNOLOGIES INVOLVED}

The principle of the tomographic atom-probe is based on a fast measurement of small electronic charges. An order of magnitude of minimum charges to be measured may be deduced from master equations. The sensivity of measurements with respect to impact position is obtained from the first derivative of equation 1 :

$$
\frac{d\left(Q_{1}+Q_{3}\right)}{Q}=-\frac{2}{\pi} \sqrt{1-x^{2}} d x
$$

This equation indicates that the estimation of atom positions within $0.1 \mathrm{~nm}$ $(\Delta \mathrm{X}=0.1$ for $\mathrm{R}$ equivalent to $1 \mathrm{~nm})$ requires a precision $\Delta Q / Q$ close to $1 \%$. This leads to an electronic charge close to $0.16 \mathrm{pC}$ for $\mathrm{Q}=10^{8} \mathrm{e}^{-}$. A dynamic of charge distribution measurement close to 100 is sufficient to ensure an atomic scale spatially resolved image. This means that sample and hold devices which are needed do not involve a high dynamic range : a commercially available Le Croy $2249 \mathrm{~A}$ is largely sufficient for instance. Figure 4 shows a general view of whole the detection unit. Electronics is represented only for a single detector. Time of flights are measured from the back side of the channel-plate.

The general philosophy is similar to that of cur four sector detection system. The measurement is based on a fast recording of two dimensional electronic charge maps (up to 8 ) corresponding to isochronal events. These isochronal maps are rapidly shifted to the following units for each new time event : one charge map is associated to a sirgle time of flight. When no more event is waited, analog to digital conversion may proceed and digitalized isochronal charge maps may be transfered to the computer before a new evaporation pulse is applied. 


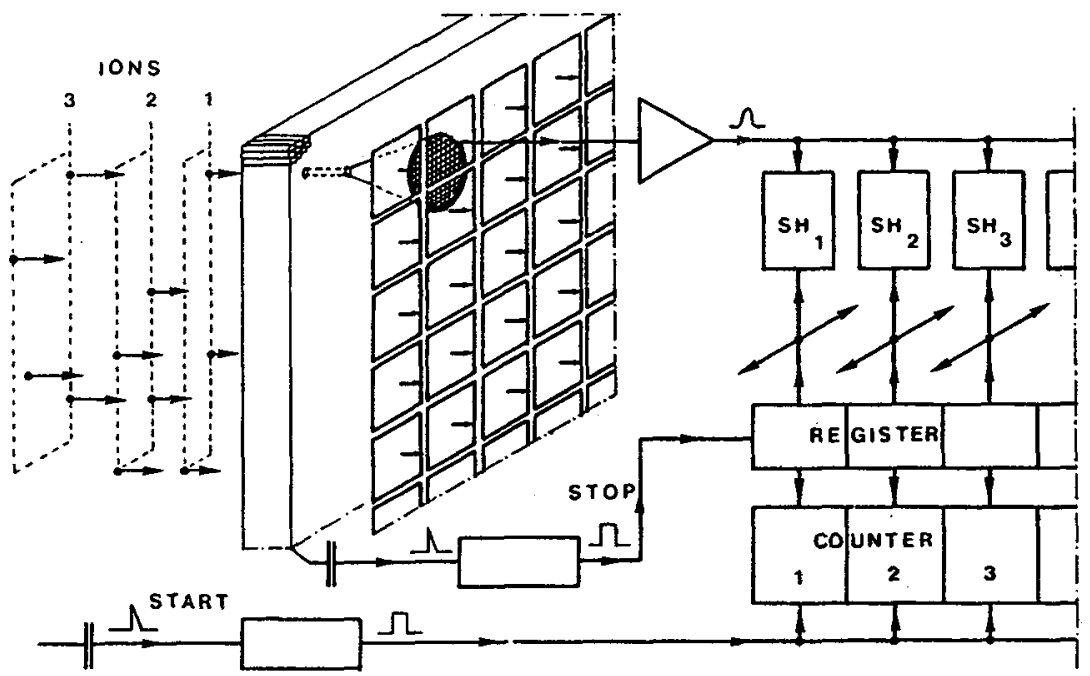

Figure 4: General view of the detection system.

\section{GONCLUSION}

The new outlooks opened by the POSAP developed by the OXFORD Group incited us to present our project : the tomographic atom-probe. The innovative technological solutions we propose lead to a new generation of instrument. Although physical features are not yet completly defined, the potential performances are attractive : for a single pulse, our two dimensional detector should allow to record multiple events even for simultaneous ions with a high efficiency.

Even for the scarce cases for which positions are difficult to be estimated (probability of failure $1 \%$ ), the maximum error for the atom position is 1 nn. The average detection flux attained by our detector is 2 ions/pulse. For instance, for a pulse frequency of $50 \mathrm{~Hz}, 3610^{4}$ ions are collected in an hour. For a typical scanned volume of $20 \times 20 \times 100 \mathrm{~nm}^{3}, 7$ hours are required to record the $2.410^{7}$ incoming ions. This order of magnitude shows that the number of calculations which are required to determine the nature as well as the position of every ion contained in this volume is huge. This means that a fast computer with large memory capacities is required.

Although our detection system is designed to provide more refined data than those of the POSAP, it is clear that the technology which is involved leads to costs which are probably well higher. The flux of basic data to be recorded is also higher.

\section{REFERENCES}

(1) A. CEREzo, T.J. GODFREY and G.D.W. SMITH - J. de Phys., 49, C6-25, (1988)

[2] J.A. PANITZ - J. Vac. Sci. Technol., 11, 206, (1974)

[3] A. CEREZO, T.J GODFREY and G.D.W. SMITH - Rev. Sci. Instrum., 59, 862, (1988)

[4] D. BLAVETTE, - BOSTEL and J.M. SARRAU - J. de Phys., 47, C2-473, (1986)

[5] T.T. TSONG, Y.S. NG and S.V. KRISHNASWAMY - Appl. Phys. Lett., 32, 778, (1978)

16] A. CEREzO, G.D.W. SMITH and A.R. WAUGH - J. de Phys., 45, C9-329, (1984) 